International Journal of Biology, Pharmacy and Allied Seiences (IJBPAS)

'A Bridge Betueen caboratory and QRendo'

WwW.ibpas.com

\title{
SELECTION OF SUITABLE METHOD FOR PREPARING NASAL MUCOADHESIVE MICROSPHERES BY MULTI-CRITERIA DECISION MODEL USING THE ANALYTICAL HIERARCHY PROCESS
}

\section{S RAJARAJAN ${ }^{* 1}$, BP RAO $^{2}$ AND S SELVAMUTHUKUMAR ${ }^{1}$}

1: Department of Pharmacy, Faculty of Engineering and Technology, Annamalai University, Annamalai Nagar, Tamilnadu, India 608002

2: Department of Pharmaceutical Technology, Karnataka College of Pharmacy, Bangalore 560064

*Corresponding Author: S Rajarajan: E Mail: pharmking@gmail.com; Mobile: +919986197560

Received $3^{\text {rd }}$ Feb. 2020; Revised $3^{\text {rd }}$ March 2020; Accepted $18^{\text {th }}$ April 2020; Available online $1^{\text {st }}$ Sept. 2020

\section{https://doi.org/10.31032/IJBPAS/2020/9.9.5206}

\section{ABSTRACT}

The current study is focus to choose the best suitable method for preparation of Clarithromycin \& Cefuroxime Axetil encapsulated Nasal Mucoadhesive microspheres by Analytical hierarchical analysis (AHP) with utilizing the multi-criteria decision making model. The Appropriate approaches of formulation using simple and effective method are revolutionizing the adoptive techniques in technology transfer in manufacture of pharmaceuticals. Mostly AHP has been utilised in almost all disciplinary areas related to decision-making problems. A four level hierarchy model was constructed with four methods of microsphere preparation methods like Spray Drying, Solvent Evaporation, Ionic Gelation and Emulsion Solvent Evaporation Lyophilisation Method as alternatives. Input Specification Related, Instrument Related, Process Related and Out Put Specification Related parameters were chosen criteria with sixteensub-criteria in this AHP model to obtain overall priority weight and ranking for the selection of suitable method using Pair-wise comparison analysis. The Emulsion - Solvent Evaporation- Lyophilisation Method has the highest value (0.92101) among the alternative method of preparations of Microspheres with order of Spray Drying method (A-2) with a value of 0.692446704 , solvent evaporation Method (M-3) with a lowest 
value of 0.599880707 . The highest priority alternative value was considered to achieve the goal, i.e., the best suitable method of preparation for Nasal Mucoadhesive Microspheres. The alternative Emulsion - Solvent Evaporation- Lyophilisation Method score 0.92101 to be chosen among other alternatives and thereby judged to be the most appropriate procedure of preparing Nasal Mucoadhesive Microspheres.

\section{Keywords: Analytical hierarchical analysis, Multi Decision criteria analysis, Nasal Microspheres, priority weights}

\section{INTRODUCTION}

Nasal drug delivery is the primary choice for the treatment over local and systemic nasal mucosa disorders additionally it represents a desirable choice route because of systemic drug transport due to fairly substantial surface area, high vascularisation, excellent permeability and minimum enzymatic activity over nasal respiratory mucosa. In addition, the opportunity of direct nose-to-brain transport by means of olfactory then trigeminal neural path can also result within large development within the scientific therapy about neurological issues [1]. Many examples concerning nasal administration including systemic diffusion of drug like metoprolol, biotherapeutics. Out of which someof the products were marketed, such namely Miacalcin ${ }^{\circledR} \quad$ (Novartis, $\quad$ East Hanover, USA) or Minirin ${ }^{\circledR} \quad$ (Ferring Pharmaceuticals, Saint-Prex, Switzerland), which contain salmon calcitonin and desmopressin, respectively. Since the primary site in the body exposed for inhaled antigens the nasal cavity considered primary potential immunization site for vaccine administration [2].

Attention on innovative mucoadhesive drug delivery systems in combination along suitable transport drugs represents rational and beneficial approach for the enchantment of therapeutic effect concerning to nasally administered drug. Dry powder Polymeric microsphere formulations are high hope in nasal drug delivery systems with many benefits of liquid formulations comprising delayed mucociliary clearance, Improved drug concentration at the target site and enhanced stability [3]. The physicochemical characteristics of Particle size and distribution, Polymer molecular weight, Ratio of drug to polymer, Total mass of drug and polymer, each of these will be associated with the manufacture microspheres will relate in control of drug release. Microspheres are regularly solid, approximately spherical particles comprising of dispersed drug in either solution or microcrystalline form. Encapsulation of drugs can be achieved by 
entrapment while preparation. A number of techniques are available for the preparation of microspheres that include co-acervation phase separation, Solvent evaporation, emulsion solvent evaporation, and spray drying and Ionic gelation methods [4].

It is essential to systemic approach of the decision-making process by analytic hierarchy process was developed at the Wharton School of Business by Saaty [5]. This decision-making tool is flexible weighted scoring decision making process to assistance on to set priorities and makes the best decision. It was utilised in academic research and in industrial practice in decision making. Now mostly followed in fields of engineering, pharmaceuticals, and personal and social areas [6]. In this Complex decisions can be narrowing to an order of pairwise comparisons and then the conclusion is attained from the overall analysis in each level. Confirming the reliability of assessments helps decrease the bias. In the selection of method for preparation of nanoparticles was carried out systematically with an example [7].

This current study of analytic hierarchy process (AHP), a MCDM tool has been used mainly to deliberate AHP implementation in the area of the method selection process among Spray Drying, Solvent Evaporation, Ionic Gelation and Emulsion Solvent Evaporation Lyophilisation Method for preparation of nasal mucoadhesive microspheres. This methodology utilised to minimise the process, time and produce higher product quality with robustness.

\section{MATERIALS AND METHODS}

\section{Analytical Hierarchy Process}

In this method, hierarchical model consists of goal, criteria, sub-criteria and alternatives are constructed. AHP is composed of several previously existing but unassociated concepts and techniques, such as hierarchical structuring, pair-wise comparisons for deriving weights and consistency considerations. Once a hierarchy framework has been constructed, Handlers are requested in conformity with accept on a pairwise assessment at each level hierarchy and compare options with the aid of using a pairwise comparison. According in conformity with saaty scale was shown in Table 1. The step wise process involved in principles was elaborated by structuring them in a more encompassing nine steps as shown in Figure 1 [8]. According to saaty, the method has three phases: 1) Assigning Goal and Criteria 2) Analysis of criteria, 3) Synthesizing reports [9].

In First Phase, the elements of decision problem are arranged in form of hierarchy. The top elements of hierarchy is overall goal, the next level is the criteria which impact the goal directly, the next level is the operational sub-criteria, against which 
the decision alternatives of the lowest level of hierarchy can be evaluated and all the elements of a given level are assumed to be mutually independent [9].

In Analysis of Criteria Phase, elements of one level of a hierarchy are compared pairwise as to the strength of their influence on an element of the next higher level. Saaty has suggested a scale of 1 to 9 when comparing two elements, with a score of 1 representing indifference between the two elements and 9 representing the overwhelming dominance of that element over the other. These comparison leads to dominance matrices which are called pairwise comparison matrices [9].

The next phase is to synthesizing the results with priorities, the simple hierarchical model which evaluates alternatives with respects to criteria and sub-criteria of overall goal. The priorities of all alternatives with respect to each criterion are calculated. The Performance sensitivity analysis with respect to Goal and other four main criteria were analysed. The overall priorities weights are calculated from pairwise comparison matrix [9]. Figure 3 shows the flow chart of the AHP methodology.

\section{Hierarchy Model}

The study of four level hierarchy model for the selection of suitable method for the preparation of Clarithromycin \& Cefuroxime Axetil encapsulated Nasal
Mucoadhesive microspheres. The first level represents the goal of the hypothesis. The objective of the model is divided into four main criteria were shown in the Table 3 are given as proposed hierarchical model [9].

\section{Main Criteria and Sub-Criteria}

Selection of safe and potential alternatives for the preparation of nasal mucoadhesive microspheres as well as selecting the related main criteria and sub-criteria Table $\mathbf{1}$ are based on the justification as described in the Table 3. As per the detailed literature survey the potential methods or alternatives selected for the preparation of nasal mucoadhesive microspheres were chosen based the details literature.

The recent advancement of preparation of microspheres by researchers was obtained with many reports of modified techniques like ionotropic gelation, Spray drying, ionotropic gelation, multiple emulsionsolvent evaporation and Free radical polymerisation method [10].

Formulation of these alginate microspheres (AMS) are commonly achieved by conventional external gelation method using various instrumental manipulation such as vortexing, homogenization, ultrasonication or spray drying, and each method affects the overall particle characteristics. Fabrications of alginate microspheres AMS can be formulated through techniques such as single/double emulsion, extrusion, spray drying, or 
microfluidics methods. Conventionally, water in oil single emulsion is the most common method used for formulation [11]. Further, have concluded that (i) there is a variety of research concerning inorganic and polymeric particles, and (ii) spherical micro- and nanoparticles are being developed to serve as or to build functional devices. The number of publications concerning biopolymer-based structures has increased recently to fulfil the need for novel applications [12-13].

\section{Determination of Priority Weight and}

\section{Ranking}

In hierarchy model, for selecting the suitable method, Determination of Priority Weight and Ranking followed by the first level is the overall objective. The Figure 4 also shows the four main criteria in the second, sixteen sub-criteria in the third and four alternatives in the last level. Assessment of the criteria weights are developed using the pair-wise comparison [14 -16].

According to AHP method, the elements of each level are pair-wise compared with the elements of next higher level resulting in a number of pair-wise comparison matrixes. The pair-wise comparisons were made using the saaty's scale in Table 1.

\section{RESULTS AND DISCUSSION}

Pair-wise comparison matrix results were shown in Table 4 was constructed by allocating the weights to all the elements using the saaty's scale. All the constructed pair-wise comparison matrixes were found to be consistent, as the consistency ratio was $<0.1$. Hence, the weights allotted were reasonable. From the pair-wise comparison matrix, priority weights from each subcriterion are calculated and ranks are assigned based on overall priority weights. Table 4 shows the overall priority weight and ranking of potential eight alternatives obtained from AHP methods. The sensitivity investigation performance of the decisions made is shown in the Figure 3.

AHP technique benefits to select the best choice among four alternatives for the preparation of nasal mucoadhesive microspheres like ESL, SPD, SEM and IGM. In this AHP method of analysis which is used to evaluate and choose the best alternative based on the criteria and sub-criteria aspects of the decision based on their overall pair wise analysis with prioritisation and followed by performance analysis results. From the Table 4 the overall priority ranking of techniques of all the alternatives in all the levels, the problem involves the finding of composite scores reflects the relative priorities of all the alternatives at the lowest level of the hierarchy. The overall rating of alternates was observed in the order of ESL (0.319), IGM (0.243), SPD (0.240), and SEM (0.198) for the preparation of nasal mucoadhesive microspheres. The Emulsion 
- Solvent Evaporation- Lyophilisation

Method was implemented to prepare

Clarithromycin \& Cefuroxime Axitil encapsulated Nasal Mucoadhesive

microspheres.

\begin{tabular}{|c|c|}
\hline Step 1 & - Define Hypothesis \\
\hline Step 2 & - Develop the hierarchical model \\
\hline Step 3 & $\begin{array}{c}\text { - Assign the Goal, Criteria, Sub-criteria and } \\
\text { Alternatives }\end{array}$ \\
\hline Step 4 & $\begin{array}{c}\text { - Construct and Analyse pair-wise comparison of } \\
\text { criteria }\end{array}$ \\
\hline Step 5 & -Synthesis pair-wise comparisons \\
\hline Step 6 & - Check for consistency \\
\hline Step 7 & - Perform Step [3 \& 6] for all level in hierarchy \\
\hline Step 8 & - Develop Overall priority ranking \\
\hline Step 9 & - Select the best Alternative \\
\hline
\end{tabular}

Figure 1 AHP Methodology Flow Chart

Table 1: Saaty Scores for the importance of variable

\begin{tabular}{|c|c|}
\hline Importance Scale & Definition of Importance Scale \\
\hline $\mathbf{1}$ & Equally Important Preferred \\
\hline $\mathbf{2}$ & Equally to Moderately Important Preferred \\
\hline $\mathbf{3}$ & Moderately Important Preferred \\
\hline 5 & Moderately to Strongly Important Preferred \\
\hline 6 & Strongly Important Preferred \\
\hline 7 & Strongly to Very Strongly Important Preferred \\
\hline 8 & Very Strongly Important Preferred \\
\hline 9 & Very Strongly to Extremely Important Preferred \\
\hline
\end{tabular}

Table 2: Sample AHP Questionnaire

\begin{tabular}{|c|c|c|c|c|c|c|c|c|c|c|c|c|c|c|c|c|c|c|}
\hline Factor & $\mathbf{9}$ & $\mathbf{8}$ & $\mathbf{7}$ & $\mathbf{6}$ & $\mathbf{5}$ & $\mathbf{4}$ & $\mathbf{3}$ & $\mathbf{2}$ & $\mathbf{1}$ & $\mathbf{2}$ & $\mathbf{3}$ & $\mathbf{4}$ & $\mathbf{5}$ & $\mathbf{6}$ & $\mathbf{7}$ & $\mathbf{8}$ & $\mathbf{9}$ & Factor \\
\hline $\begin{array}{c}\text { Instrument } \\
\text { Related }\end{array}$ & $\mathbf{9}$ & $\mathbf{8}$ & $\mathbf{7}$ & $\mathbf{6}$ & $\mathbf{5}$ & $\mathbf{4}$ & $\mathbf{3}$ & $\mathbf{2}$ & $\mathbf{1}$ & $\mathbf{2}$ & $\mathbf{3}$ & $\mathbf{4}$ & $\mathbf{5}$ & $\mathbf{6}$ & $\mathbf{7}$ & $\mathbf{8}$ & $\mathbf{9}$ & $\begin{array}{c}\text { Out Put } \\
\text { Specification } \\
\text { Related }\end{array}$ \\
\hline $\begin{array}{c}\text { Process } \\
\text { Related }\end{array}$ & $\mathbf{9}$ & $\mathbf{8}$ & $\mathbf{7}$ & $\mathbf{6}$ & $\mathbf{5}$ & $\mathbf{4}$ & $\mathbf{3}$ & $\mathbf{2}$ & $\mathbf{1}$ & $\mathbf{2}$ & $\mathbf{3}$ & $\mathbf{4}$ & $\mathbf{5}$ & $\mathbf{6}$ & $\mathbf{7}$ & $\mathbf{8}$ & $\mathbf{9}$ & $\begin{array}{c}\text { Input } \\
\text { Specification } \\
\text { Related }\end{array}$ \\
\hline $\begin{array}{c}\text { Input } \\
\text { Specification } \\
\text { Related }\end{array}$ & $\mathbf{9}$ & $\mathbf{8}$ & $\mathbf{7}$ & $\mathbf{6}$ & $\mathbf{5}$ & $\mathbf{4}$ & $\mathbf{3}$ & $\mathbf{2}$ & $\mathbf{1}$ & $\mathbf{2}$ & $\mathbf{3}$ & $\mathbf{4}$ & $\mathbf{5}$ & $\mathbf{6}$ & $\mathbf{7}$ & $\mathbf{8}$ & $\mathbf{9}$ & $\begin{array}{c}\text { Process } \\
\text { Related }\end{array}$ \\
\hline $\begin{array}{c}\text { Out Put } \\
\text { Specification } \\
\text { Related }\end{array}$ & $\mathbf{9}$ & $\mathbf{8}$ & $\mathbf{7}$ & $\mathbf{6}$ & $\mathbf{5}$ & $\mathbf{4}$ & $\mathbf{3}$ & $\mathbf{2}$ & $\mathbf{1}$ & $\mathbf{2}$ & $\mathbf{3}$ & $\mathbf{4}$ & $\mathbf{5}$ & $\mathbf{6}$ & $\mathbf{7}$ & $\mathbf{8}$ & $\mathbf{9}$ & $\begin{array}{c}\text { Instrument } \\
\text { Related }\end{array}$ \\
\hline
\end{tabular}


Table 3: Explanation of Selected Criteria relevant to Sub-Criteria

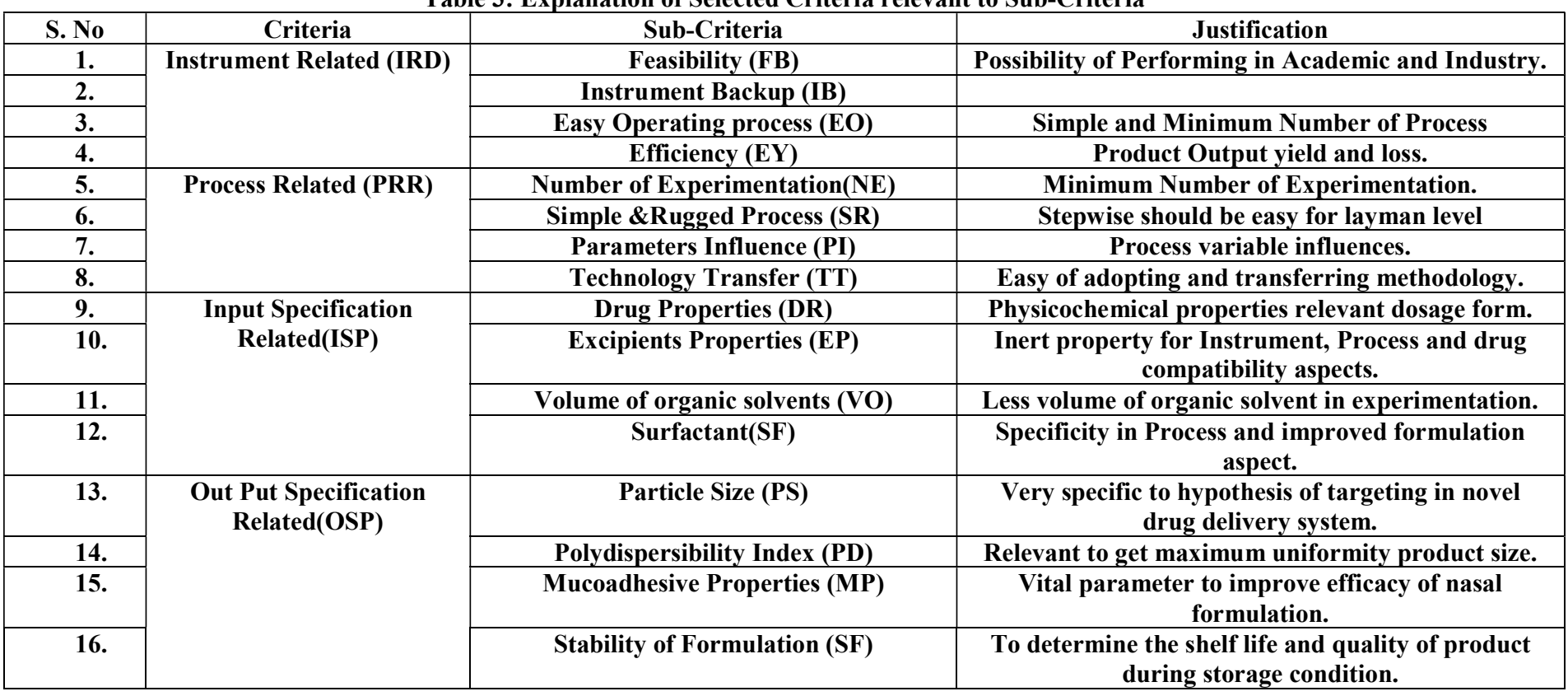

Table 4: Synthesis results score for each of the alternatives

\begin{tabular}{|c|c|c|c|c|c|c|c|c|}
\hline \multirow{3}{*}{$\begin{array}{c}\text { Level } 1 \\
\text { (Criteria) }\end{array}$} & \multirow{3}{*}{$\begin{array}{l}\text { PR } \\
\text { WT }\end{array}$} & \multirow{3}{*}{$\begin{array}{c}\text { Level } 2 \\
\text { (Sub- } \\
\text { Criteria) } \\
\end{array}$} & \multirow{3}{*}{$\begin{array}{l}\text { PR } \\
\text { WT }\end{array}$} & \multirow{3}{*}{$\begin{array}{c}\% \text { PR } \\
\text { WT }\end{array}$} & \multicolumn{4}{|c|}{ Alternates } \\
\hline & & & & & ESL & SPD & SEM & IGM \\
\hline & & & & & PR WT & PR WT & PR WT & PR WT \\
\hline \% Out Put Specification Related & & & & 34.4 & & & & \\
\hline \multirow{4}{*}{ Out Put Specification Related } & 0.345 & PS & 0.648 & 22.3 & 0.084 & 0.076 & 0.025 & 0.038 \\
\hline & & PI & $\mathbf{0 . 0 3 7}$ & 1.2 & 0.005 & 0.004 & 0.001 & 0.002 \\
\hline & & MP & 0.227 & 7.8 & 0.027 & 0.017 & 0.011 & 0.023 \\
\hline & & SF & $\mathbf{0 . 0 8 8}$ & 3 & 0.011 & 0.008 & 0.003 & 0.008 \\
\hline \% Process Related & & & & 23.3 & & & & \\
\hline \multirow[t]{4}{*}{ Process Related } & 0.233 & $\mathbf{N E}$ & 0.052 & 1.2 & 0.003 & 0.002 & 0.003 & 0.004 \\
\hline & & SR & 0.281 & 6.5 & 0.017 & 0.01 & 0.014 & 0.024 \\
\hline & & PI & 0.511 & 11.9 & 0.029 & 0.026 & 0.036 & 0.028 \\
\hline & & TT & 0.157 & 3.7 & 0.009 & 0.011 & 0.007 & 0.01 \\
\hline$\%$ Instrument Related & & & & 22.3 & & & & \\
\hline \multirow[t]{4}{*}{ Instrument Related } & 0.225 & FY & 0.452 & 10.2 & 0.03 & 0.017 & 0.023 & 0.032 \\
\hline & & IB & 0.133 & 2.9 & 0.008 & 0.004 & 0.009 & 0.008 \\
\hline & & EP & 0.167 & 3.7 & 0.011 & 0.005 & 0.011 & 0.01 \\
\hline & & EY & 0.248 & 5.5 & 0.012 & 0.012 & 0.018 & 0.013 \\
\hline \% Input Specification Related & 0.198 & & & 19.9 & & & & \\
\hline \multirow[t]{4}{*}{ Input Specification Related } & & DP & 0.163 & 3.3 & 0.013 & 0.006 & 0.004 & 0.01 \\
\hline & & EP & 0.362 & 7.2 & 0.023 & 0.013 & 0.017 & 0.019 \\
\hline & & VO & 0.225 & 4.4 & 0.016 & 0.013 & 0.009 & 0.006 \\
\hline & & SF & 0.250 & 5 & 0.02 & 0.014 & 0.007 & 0.009 \\
\hline
\end{tabular}




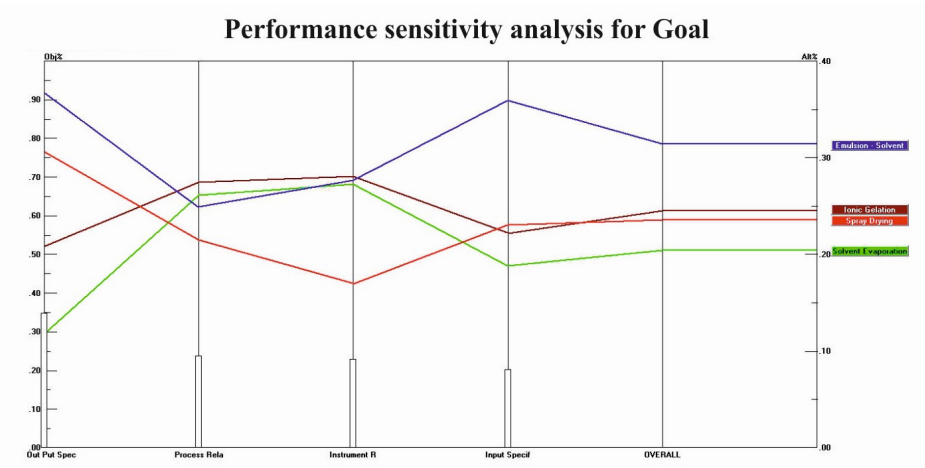

Performance sensitivity analysis for Criteria (IRD) with respect to sub criteria.

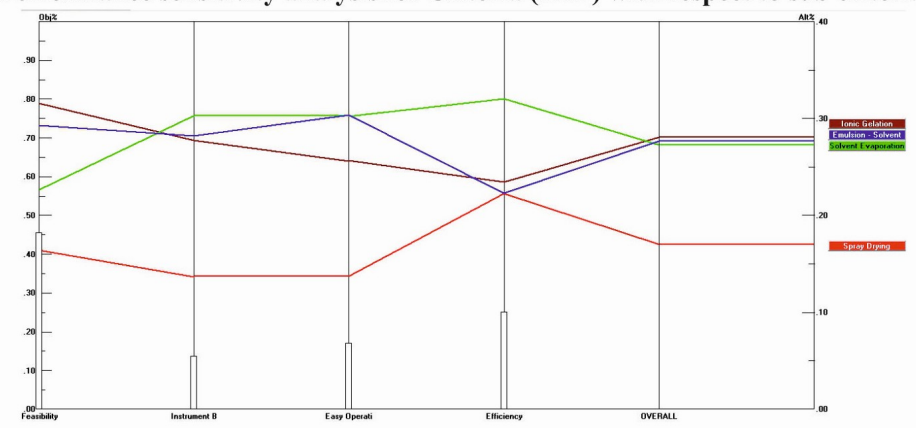

Performance sensitivity analysis for Criteria (PRR) with respect to sub criteria.

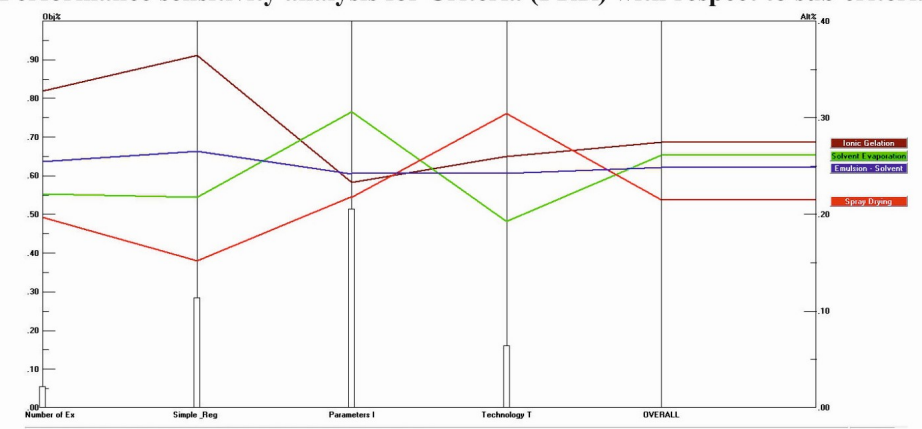

Performance sensitivity analysis for Criteria (ISP) with respect to sub criteria.

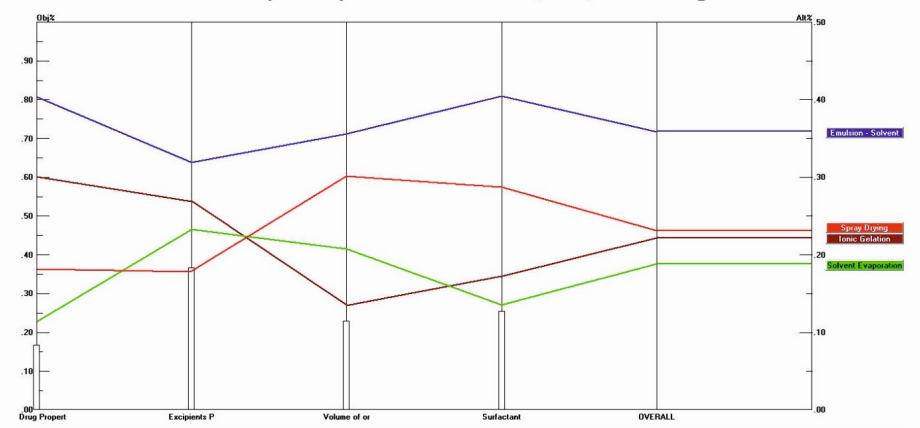

Performance sensitivity analysis for Criteria (OSP) with respect to sub criteria.

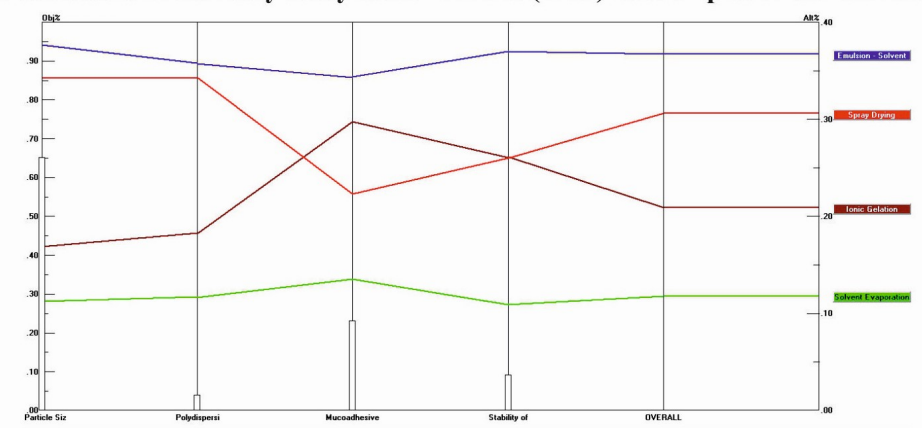

Figure 3: Performance sensitivity analysis with respect to Goal and other four main criteria 


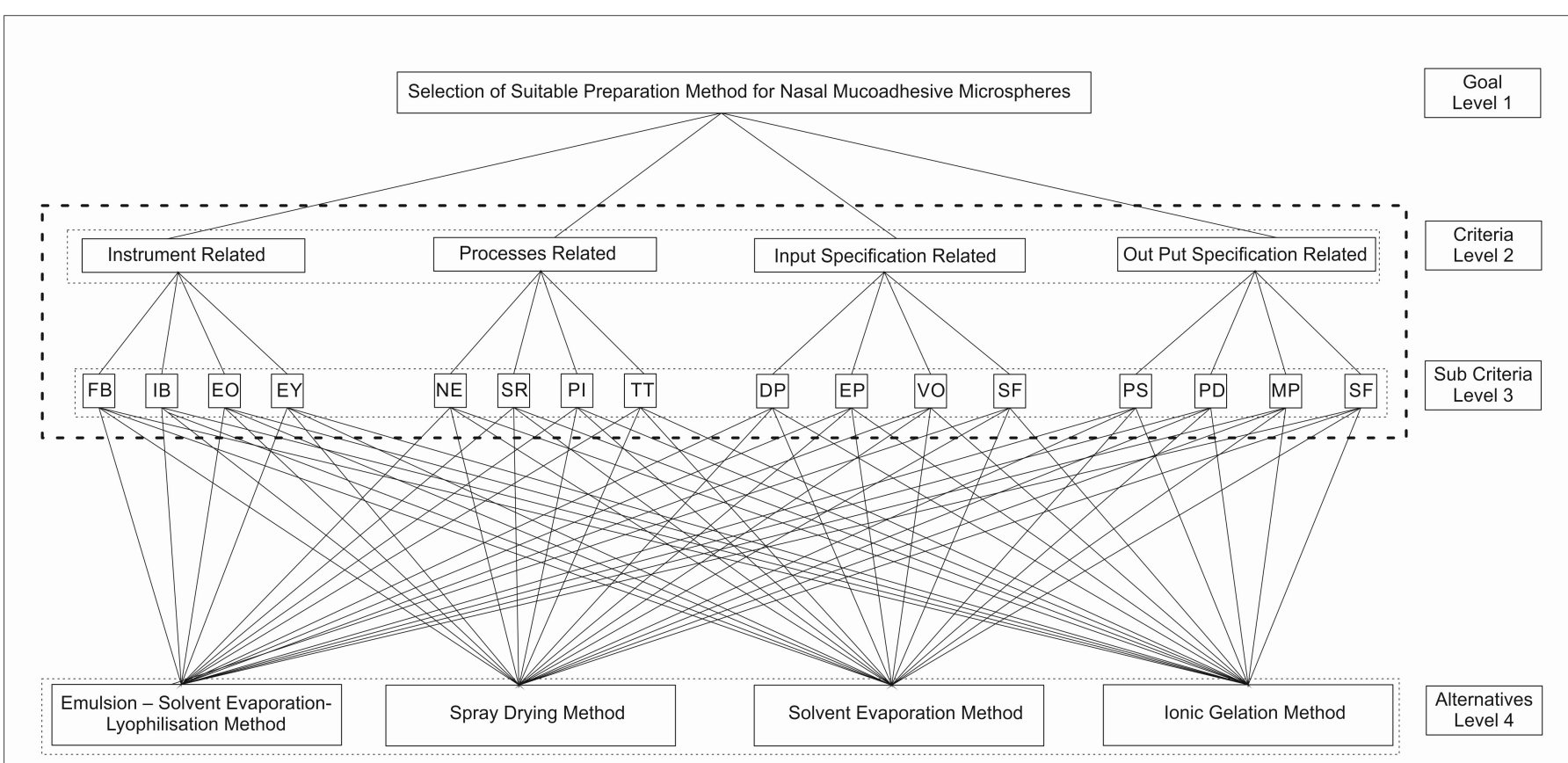

Figure 4: AHP Hierarchy structure of nasal mucoadhesive microspheres preparation method selection

\section{CONCLUSION}

In conclusion, an operational basis for formulation of Clarithromycin \& Cefuroxime Axetil encapsulated Nasal Mucoadhesive microspheres using AHP as MCDM tool is incorporated in this study here. The analysis reveals that Emulsion Solvent Evaporation- Lyophilisation Method, is the most appropriate for the preparation of Mucoadhesive microspheres because it has the highest value $(0.319$ or $34.4 \%$ ) than other methods. This approach is a systematic one and it includes both quantitative and qualitative factors. The factors considered here are illustrative only and these may vary from case to case. The projected model shall be utilised in other aspects in the formulation stages situations like selection of alternatives such as microsphere formulation techniques, characterization technique involved in physicochemical parameters.

\section{REFERENCE}

[1] Djupesland PG. Nasal drug delivery devices: characteristics and performance in a clinical perspective-a review. Drug Deliv Transl Res. 2013; 3(1): 42-62. doi:10.1007/s13346-012-0108-9.

[2] Csaba, N., Garcia-Fuentes, M., Alonso, M.J., 2009. Nanoparticles for nasal vaccination. Adv. Drug Deliv. Rev. 61, 140-157.

[3] Tiozzo Fasiolo, L., Manniello, M.D., Tratta, E., Buttini, F., Rossi, A., Sonvico, F., Bortolotti, F., 
Russo, P., Colombo, G., 2018.

Opportunity and challenges of nasal powders: drug formulation and delivery. Eur. J. Pharm. Sci. 113, 2 17.

[4] Diane J. B, Anthony J. H. Microsphere Technology and Applications. Encyclopaedia of pharmaceutical technology. Third Edition. Volume 4. Informa Healthcare USA, New York. 23282338.

[5] Saaty TL (1980) The Analytic Hierarchy Process. New York, McGraw Hill.

[6] Vaidya OS, Kumar S (2006) Analytical Hierarchy Process, an overview of applications. Eur J Operational Res 169: 1-29.

[7] Velmurugan, R., Selvamuthukumar, S., and Manavalan, R. (2011). Multi criteria decision making to select the suitable method for the preparation of nanoparticles using an analytical hierarchy process, Die Pharmazie-An International Journal of Pharmaceutical Sciences, 66(11), 836-842.

[8] Lee. M. C. A Method of Performance Evaluation by Using the Analytic Network Process and Balanced Score Card, International Conference on Convergence Information Technology. 2007.
[9] Murat BC, Meral S. The analytic hierarchy and Analytic network processes. Hacet J Math Stat 2003; 32: $65-73$.

[10] Małgorzata Stanisz, Łukasz Klapiszewski, Teofil Jesionowski. Recent advances in the fabrication and application of biopolymerbasedmicro- and nanostructures: A comprehensive review. Chemical Engineering Journal 397 (2020) 125409.

[11] Dinesh Dhamecha, Rachel Movsas, Ugene Sano, Jyothi U. Menon. Applications of alginate microspheres in therapeutics delivery and cellculture: Past, present and future. Int. J. Pharm.569 (2019) 118627.

[12] Debabrata Ghosh Dastidar, Sourabh Saha, Moumita Chowdhury. Porous microspheres: Synthesis, characterisation and applications inpharmaceutical \& medical fields. Int. J. Pharm. 548 (2018) 34-48.

[13] Chun Y. Wonga B, Hani AlSalamia,B, Crispin R. Dassa. Microparticles, microcapsules and microspheres: A review of recent developments and prospects for oral delivery of insulin.Int. J. Pharm. 537 (2018) 223-244. 
[14] Saaty TL. The analytical hierarchy process: planning, priority setting, resource allocation. New York: McGraw-Hill International Book Co; 1980.

[15] Saaty TL. Relative measurement and its generalization in decision making: Why pair-wise comparisons are central in mathematics for the measurement of intangible factors, the analytic hierarchy/network process. Rev R Acad Cien Serie A Mat 2008; 102(2): 251-318.

[16] Perez-Vegaa S, Peter S, SalmeronOchoa I, Nieva-de la Hidalga A, Sharratt PN. Analytical hierarchy processes (AHP) for the selection of solvents in early stages of pharmaceutical process Development. Process Saf Environ Prot 2011; 89(4): 261-7. 